\title{
Shame, sensitivity to punishment and psychiatric disorders
}

\author{
José Guimón, M.D* \\ Carlota Las Hayas, Psychologist ${ }^{\star *}$ \\ Virginia Guillén, Ph.D* \\ Aizpea Boyra, Psychologist* \\ Asunción González-Pinto, Ph.D* \\ * Research Unit. Galdacano Hospital. \\ Vizcaya \\ ** Departament of Neurosciences. \\ Psychiatry. Faculty of Medicine and \\ Odontology. Basque Country University. \\ SPAIN
}

\begin{abstract}
Background and objectives: Various studies have found significant correlations between feelings of shame and psychopathologies, as depression or eating disorders. Since some authors have shown an association between inhibition, neuroticism and shame, we hypothesize that Sensitivitybility to Punishment (SP) would relate positively to shame. We also propose that patients diagnosed with depression should score higher in shame domain than the rest of the diagnostic groups. Finally we predict that psychotic patients, since they have poor self-consciousness, should score the lowest in shame proneness.

Methods: The Spanish version of the TOSCA, the Sensitivity to Punishment and Reward Questionnaire (SPSRQ) and The Clinical Global Impressions (CGI) were applied to a sample of 172 individuals, from which 93 were university students and 79 were patients receiving psychiatric treatment.

Results: In the Sensitivity to Punishment domain we found statistically significant mean differences between patients with Major Depression and the comparative group. We have found a positive correlation between Sensitivity to Punishment and Shame in the general population and also for the Major depressive subgroup. The relation between depression and shame proneness was statistically significant. Shame and Guilt correlated in the TOSCA and the Major Depressive patients scores higher on both domains. Bipolar and schizophrenics patients showed lower scores in Shame than depressives.

Conclusions: Among other conclussions we recomend that future studies in the field should use dimensional diagnoses besides the categorial ones.
\end{abstract}


For the Oxford Encyclopedia of Philosophy ${ }^{1}$ 'Shame' is the feeling of being exposed to the moral criticism of others, "in particular when one feels tempted to cross the basic levels of decency or integrity (...). To be ashamed of oneself is not only to recognize one's own objective fault, but rather also involves a painful and sad awareness of moral failure, a feeling of loss of esteem and selfesteem, a desire to hide out of sight of others"

Shame has been related to other personality traits and states. It could be considered equivalent to self-accusatory guilt, but in the eyes of others, as an inseparable member of a group or community.

Shyness moderately correlates with introversion and the psychiatric comorbidity in shy people is significantly greater than in people who are not $s^{2}{ }^{2}$. Shyness does not always precede social phobia ${ }^{3}$, although it is more prevalent in shy people (18\%) than in people that are not shy (3\%). Most shy people $(82 \%)$ are not socially phobic.

Social anxiety is defined as "an intense and persistent fear of social situations or those in which one deals with the public". It is present in $13 \%$ of the population and can be very disabling, sometimes coexisting with depression or dysthymia. Shyness and social phobia (in particular the variety Gelder called 'generalized') are similar but not identical because an individual can be extremely shy and not have social phobia ${ }^{4}$.

Among some neighbor concepts, we want to stress the relation of shame with 'Inhibition', a generally reversible active functional process, which suspends or reduces the manifestation of another physiological mechanism which is put into action ${ }^{5}$. Its intervention explains many biological phenomena like blocking of some dangerous reflexes, death by inhibition, psychic sexual impotence, etc.
Gray's model of personality postulates the existence of specific neurological systems influencing sensitivity to reinforcing or inhibiting (i.e. punishment) events. A Susceptibility to Punishment Scale ${ }^{6}$ was created in order to measure Gray's anxiety dimension and Muntaner \& Torrubia ${ }^{7}$ developed the Susceptibility to Reward Scale to measure impulsivity. Later on Torrubia et al. created the Sensitivity to Punishment and to Reward Questionnaire (SPSRQ).

The Sensitivity to Reward Scale was positively related to Eysenck's Extraversion and Neuroticism dimensions, moderately related to Psychoticism and positively related to Eysenck's Impulsiveness and the Zuckerman's Sensation Seeking scales. On the other hand, Torrubia et al point out that sensitivity to punishment as measured by the SPSR is positively related to neuroticism.

There is evidence in the literature that shame proneness is associated with a variety of indices of psychopathology ${ }^{8}$. Tangney ${ }^{9}$ has found an association between shame and anxiety. Depressive subjects show high scores in shame-proneness.

In this article we want to offer the results of a study in which we compared normal subjects versus psychiatric patients with different psychiatric condition. Since some authors have shown an association between inhibition, neuroticism and shame, we hypothesize that Sensibility to Punishment (SP) would relate positively to shame. We also propose that patients diagnosed with depression should score higher in shame domain than the rest of the diagnostic groups. Finally we predict that psychotic patients, since they have poor selfconsciousness, should score the lowest in shame proneness. 


\section{Methods}

\section{Subjects}

A total of 172 persons were recruited. Specifically, 93 were university students and 79 were psychiatric patients.

Patients were receiving psychiatric treatment in an outpatient or inpatient basis. A member of the research team in collaboration with the psychologists attending these patients was the responsible of administering the battery of tests. In order to complete the questionnaire patients had to give their voluntary consent to participate in the investigation The clinicians who were attending these patients had to complete a data sheet where they had to provide the diagnosis of the patient according to the Diagnostic and Statistical Manual-IV (American Psychiatric Association, 1994). The distribution of DSM-IV diagnosis were as follows: 20 (25.3\%) presented a Depressive Disorder; 12 (15.2\%) a Bipolar Disorder; 15 (19\%) an Anxiety Disorder; 15 (19\%) presented a Psychotic Disorder; and 17 (21.5\%) presented a Personality Disorder (borderline or antisocial). The mean age of the psychiatric sample was 40.25 $(\mathrm{SD}=14.0)$ years old; $55.7 \%$ were female; $27.8 \%$ had attained a graduate degree, while $38 \%$ had reached secondary education; $30.4 \%$ were full time workers, $17.7 \%$ persons with disabilities; $12.7 \%$ housekeepers, and $13.9 \%$ were off sick.

Exclusion criteria were age above 65 , substance abuse and dementia.

A sample of 93 University students was recruited among those attending second and third year courses of the Medical curriculum. The mean age of the recruited student sample was $19.47(\mathrm{SD}=1.4)$ years old; $78.5 \%$ were of female gender; $98.9 \%$ of the total sample was single, and $88.2 \%$ were studying as their main working activity.

\section{Instruments}

We used the Sensitivity to Punishment and Sensitivity to Reward Questionnaire $(\text { SPSRQ })^{10}$, the version 1 of the TOSCA ${ }^{11}$, the Clinical Global lmpression (NIMH, 1976) and a socidemographic questionnaire created on purpose by the research team.

The TOSCA is a scenario-based measure of guilt-and shame proneness, in which participants rate on a series of 5 point ordinal scale their likelihood of responding to 15 situations in ways that have been pre-coded to reflect guilt, shame, externalization of blame, detachment/unconcern, pride in self and pride in behavior. TOSCA's reliability examination was tested through Cronbach alpha analyses for each of the 6 subscales of the TOSCA. Validity was good. Reliability was considered low for some subscales as alpha and beta pride, and moderate to good for the remaining domains ${ }^{12}$ had obtained Cronbach alpha of 0.75 for the guilt scale and 0.82 for the shame scale. The TOSCA has been preliminarily validated in a Spanish sample showing satisfactory results ${ }^{13}$.

The Sensitivity to Punishment and to Reward Questionnaire, SPSRQ ${ }^{10,14}$ is a 48 yes-no response items questionnaire containing two scales: Sensitivity to Punishment (SP: a 24-items revised version of the Susceptibility to Punishment scale) and Sensitivity to Reward (SR: a definitive version including 24 items). The Sensitivity to Punishment Scale (SP) included items that measured individual differences in some functions dependent on the Behavioral Inhibition System of the Gray's model: behavioral inhibition, in general situations involving the possibility of aversive consequences of novelty; and worry or cognitive processes produced by the threat of punishment or failure. The items related to Sensitivity to Reward Scale (SR) included items that measured differences in the impulsivity dimension 
following Gray's description of the BAS (Behavioral Activation System). These items include topics such as money, sex partners, social events, power, sensation-seeking and so on, trying to describe situations in which people could do something to obtain rewards ${ }^{10}$. Internal consistency and test-retest reliability reached acceptable levels for both scales, these being higher for the SP scale (0.89 in 3 months; 0.74 in 1 year) than SR scale ( 0.87 in 3 months; 0.69 in 1 year). The Cronbach's alpha was 0.83 for SP and 0.78 in SR. The authors have provided support for the validity of the SPSRQ, they used in different studies ${ }^{6,10,15}$.

\section{Statistical procedures}

Descriptive analyses were performed to examine the sociodemographic characteristics of the sample. Firstly, an ANOVA was made to evaluate whether there were differences in means between the various diagnostic groups. As in the ANOVA, the more groups we compare, the less accurate are the comparisons, we performed an ANOVA for a general overview of the results, and afterwards we applied the Student t-test to compare the diagnostic groups by pairs. Pearson's correlation coefficients were employed to examine associations among the subscales, in a intragroup level. The maximum significance level was set at $\mathrm{p}<0.05$.

The SPSS 11.0 statistical program was used to perform all the analyses.

\section{Results}

\section{Shame and Sensitivity to Punishment}

In this article we are going to focus on the Shame and SP domains, although some results of the remaining scales will be also mentioned below. The ANOVA found significant differences among the five diagnosis groups. The Student t-test showed that Depressive disordered patients (mean = $46.35 \pm 11.15$ ) scored 9.6 points higher in Shame than Bipolars $($ mean $=36.75 \pm 8.80)$ $(\mathrm{p}=0.017)$ and 10.02 points higher than Schizophrenia $($ mean $=36.33 \pm 6.11)$ Disordered patients $(\mathrm{p}=0.04)$. The comparative group scored 6.7 points higher in shame than Bipolars. From these results we could assert that Schizophrenics and Bipolar patients are the subgroups that show a higher 'proneness to shamelessness'.

In the Sensitivity to Punishment domain we only found statistically significant mean differences (see Table I) between patients with Major Depression $($ mean $=16.1, \mathrm{SD}=$ 5.5 ) and the comparative group (mean = 11.8, $\mathrm{SD}=5.4$ ).

We have found a positive correlation between Sensitivity to Punishment, and Shame $(r=0.493 ; \mathrm{p}<0.05)$ in the general population and also for the Major depressive subgroup $(r=0.62, \mathrm{p}<0.01)$. 
Table I

ANOVA and $t$ test comparisons of means $\mathrm{s}$ in the TOSCA and SPSRQ for the different diagnostic groups and the comparative group.

\begin{tabular}{|c|c|c|c|c|}
\hline & & $\mathrm{N}$ & Mean & $\mathrm{SD}$ \\
\hline $\begin{array}{l}\text { TOSCA SHAME } * \\
\text { Score range: } 15-75\end{array}$ & $\begin{array}{l}\text { Major Depression }^{\mathrm{a}} \\
\text { Bipolar Disorder }^{\mathrm{b}} \\
\text { Anxiety Disorder }^{\mathrm{c}} \\
\text { Schizophrenic Disorder }^{\mathrm{d}} \\
\text { Borderline or Antisocial Disorder }^{\mathrm{e}} \\
\text { Comparative group }^{\mathrm{f}}\end{array}$ & $\begin{array}{l}20 \\
12 \\
15 \\
15 \\
17 \\
93\end{array}$ & $\begin{array}{l}46.3^{\mathrm{b}, \mathrm{d}} \\
36.8^{\mathrm{a}, \mathrm{f}} \\
41.1^{\mathrm{a}} \\
36.3^{\mathrm{f}} \\
39.6 \\
43.4^{\mathrm{a}}\end{array}$ & $\begin{array}{l}11.2 \\
8.8 \\
8.2 \\
6.1 \\
9.9 \\
8,7\end{array}$ \\
\hline $\begin{array}{l}\text { DETACHMENT } \\
\text { Score range: } 10-50\end{array}$ & $\begin{array}{l}\text { Major Depression } \\
\text { Bipolar Disorder }^{\mathrm{b}} \\
\text { Anxiety Disorder }^{\mathrm{c}} \\
\text { Schizophrenic Disorder }^{\mathrm{d}} \\
\text { Borderline or Antisocial Disorder }^{\mathrm{e}} \\
\text { Comparative group }\end{array}$ & $\begin{array}{l}20 \\
12 \\
15 \\
15 \\
17 \\
93\end{array}$ & $\begin{array}{l}43.1^{\mathrm{cf}} \\
39.4^{\mathrm{a}} \\
38.3^{\mathrm{a}} \\
38.4 \\
40.1^{\mathrm{a}} \\
39.4^{\mathrm{a}}\end{array}$ & $\begin{array}{l}7.3 \\
5.2 \\
6.0 \\
7.3 \\
5.8 \\
5.6\end{array}$ \\
\hline $\begin{array}{l}\text { GUILT } \\
\text { Score range: } 15-75\end{array}$ & $\begin{array}{l}\text { Major Depression }^{\mathrm{a}} \\
\text { Bipolar Disorder }^{\mathrm{b}} \\
\text { Anxiety Disorder }^{\mathrm{c}} \\
\text { Schizophrenic Disorder }^{\mathrm{d}} \\
\text { Borderline or Antisocial Disorder }^{\mathrm{e}} \\
\text { Comparative group }^{\mathrm{f}}\end{array}$ & $\begin{array}{l}20 \\
12 \\
15 \\
15 \\
17 \\
93\end{array}$ & $\begin{array}{l}60.4^{\mathrm{ef}} \\
56.9 \\
55.6 \\
56.3 \\
56.0^{\mathrm{a}} \\
57.0^{\mathrm{a}}\end{array}$ & $\begin{array}{l}6.1 \\
7.3 \\
8.6 \\
8.9 \\
6.5 \\
6.8\end{array}$ \\
\hline $\begin{array}{l}\text { EXTERNALIZATION OF BLAME } \\
\text { Score range: } 15-75\end{array}$ & $\begin{array}{l}\text { Major Depression }^{\mathrm{a}} \\
\text { Bipolar Disorder }^{\mathrm{b}} \\
\text { Anxiety Disorder }^{\mathrm{c}} \\
\text { Schizophrenic Disorder }^{\mathrm{d}} \\
\text { Borderline or Antisocial Disorder }^{\mathrm{e}} \\
\text { Comparative group }^{\mathrm{f}}\end{array}$ & $\begin{array}{l}20 \\
12 \\
15 \\
15 \\
17 \\
93\end{array}$ & $\begin{array}{l}41.6^{\text {bdef }} \\
35.8^{\mathrm{a}} \\
36.9^{\mathrm{a}} \\
35.3^{\mathrm{a}} \\
36.0^{\mathrm{a}} \\
36.5^{\mathrm{a}}\end{array}$ & $\begin{array}{l}7.9 \\
5.3 \\
8.5 \\
7.0 \\
8.5 \\
6.6\end{array}$ \\
\hline $\begin{array}{l}\text { ALPHA PRIDE } \\
\text { Score range: } 5-25\end{array}$ & $\begin{array}{l}\text { Major Depression }^{\mathrm{a}} \\
\text { Bipolar Disorder }^{\mathrm{b}} \\
\text { Anxiety Disorder }^{\mathrm{c}} \\
\text { Schizophrenic Disorder }^{\mathrm{d}} \\
\text { Borderline or Antisocial Disorder }^{\mathrm{e}} \\
\text { Comparative group }^{\mathrm{f}}\end{array}$ & $\begin{array}{l}20 \\
12 \\
15 \\
15 \\
17 \\
93\end{array}$ & $\begin{array}{l}17.3 \\
15.5^{\mathrm{f}} \\
18.6 \\
17.3 \\
16.9 \\
17.7^{\mathrm{b}}\end{array}$ & $\begin{array}{l}4.2 \\
4.0 \\
3.9 \\
4.5 \\
5.1 \\
3.4\end{array}$ \\
\hline $\begin{array}{l}\text { BETA PRIDE } \\
\text { Score range: } 5-25\end{array}$ & $\begin{array}{l}\text { Major Depression }^{\mathrm{a}} \\
\text { Bipolar Disorder }^{\mathrm{b}} \\
\text { Anxiety Disorder }^{\mathrm{c}} \\
\text { Schizophrenic Disorder }^{\mathrm{d}} \\
\text { Borderline or Antisocial Disorder }^{\mathrm{e}} \\
\text { Comparative group }^{\mathrm{f}}\end{array}$ & $\begin{array}{l}20 \\
12 \\
15 \\
15 \\
17 \\
93\end{array}$ & $\begin{array}{l}18.1 \\
17.0 \\
19.8 \\
18.1 \\
18.8 \\
18.7\end{array}$ & $\begin{array}{l}3.9 \\
4.4 \\
3.5 \\
3.0 \\
4.0 \\
3.1\end{array}$ \\
\hline $\begin{array}{l}\text { SENSITIVITY TO PUNISHMENT } \\
\text { Score range: } 0-24\end{array}$ & $\begin{array}{l}\text { Major Depression }^{\mathrm{a}} \\
\text { Bipolar Disorder }^{\mathrm{b}} \\
\text { Anxiety Disorder }^{\mathrm{c}} \\
\text { Schizophrenic Disorder }^{\mathrm{d}} \\
\text { Borderline or Antisocial Disorder }^{\mathrm{e}} \\
\text { Comparative group }^{\mathrm{f}}\end{array}$ & $\begin{array}{l}20 \\
12 \\
15 \\
15 \\
17 \\
93\end{array}$ & $\begin{array}{l}16.1^{\mathrm{bf}} \\
10.8^{\mathrm{a}} \\
12.8 \\
13.8 \\
12.8 \\
11.8^{\mathrm{a}}\end{array}$ & $\begin{array}{l}5.5 \\
5.3 \\
7.3 \\
5.9 \\
6.4 \\
5.4\end{array}$ \\
\hline $\begin{array}{l}\text { SENSITIVITY TO REWARD } \\
\text { Score range: } 0-24\end{array}$ & $\begin{array}{l}\text { Major Depression }^{\mathrm{a}} \\
\text { Bipolar Disorder }^{\mathrm{b}} \\
\text { Anxiety Disorder }^{\mathrm{c}} \\
\text { Schizophrenic Disorder }^{\mathrm{d}} \\
\text { Borderline or Antisocial Disorder }^{\mathrm{e}} \\
\text { Comparative group }^{\mathrm{f}}\end{array}$ & $\begin{array}{l}20 \\
12 \\
15 \\
15 \\
17 \\
93\end{array}$ & $\begin{array}{r}9.1 \\
9.4 \\
7.5 \\
10.7 \\
8.1 \\
9.5\end{array}$ & $\begin{array}{l}5.2 \\
6.6 \\
4.9 \\
4.7 \\
5.1 \\
3.7\end{array}$ \\
\hline
\end{tabular}

* ANOVA showed significant differences in means between groups, at $\mathrm{p}<0.05$.

T-test showed statistically significant differences between means, at $\mathrm{p}<0.05$. 


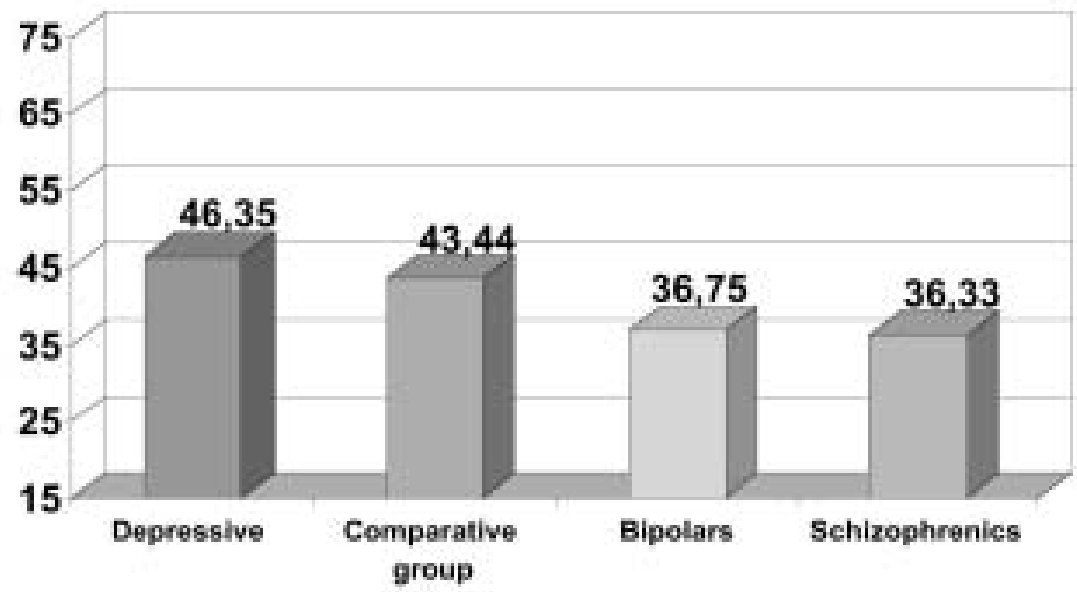

Figure 1. Shame in Depressive, Bipolar, Psychotics patiens and the comparative group.

Table II

Pearson correlations between Shame and Sensitivity to Punishment in the different diagnostic groups and in the comparative sample.

\begin{tabular}{lcl} 
& Pearson correlation & \multicolumn{1}{c}{$\mathrm{p}$} \\
\hline Major Depression $^{\mathrm{a}}$ & 0.616 & 0.004 \\
Bipolar Disorder $^{\mathrm{b}}$ & 0.059 & $\mathrm{NS}$ \\
Anxiety Disorder $^{\mathrm{c}}$ & 0.170 & $\mathrm{NS}$ \\
Schizophrenic Disorder $^{\mathrm{d}}$ & -0.176 & $\mathrm{NS}$ \\
Borderline or Antisocial Disorder $^{\mathrm{e}}$ & 0.302 & $\mathrm{NS}$ \\
Comparative group $^{\mathrm{f}}$ & 0.493 & 0.0001 \\
\hline
\end{tabular}

\section{Other findings}

Concerning the remaining subscales of the TOSCA and Sensitivity to Reward we found someinteresting results from a clinical point of view and for researchers.

Even though these remaining domains were not the focus of our research, we provide the results here because they can stimulate future researches, they are also interesting from a clinical point of view, and they may be helpful for researchers working with these instruments.

In relation to the TOSCA subdomains, it was the Major Depressive subgroup the diag- nosis which differentiate the most from the rest of the diagnostics in the TOSCA (see Table I). For the Detachment domain, Major Depressive patients scored 4.7 points higher than Anxiety disordered patients, and 3.7 points above the comparative group. For the Externalization of Blame domain, Major Depressive patients scored 5.8 points higher than Bipolars, 6.22 points higher than Schizophrenics, 5.6 points above the Borderline subgroup and 5.1 above the comparative subgroup. Regarding the Guilt domain, Major Depressive patients showed 4.35 points higher scores than Borderline patients, and 3.3 points higher than the comparative group. For the 
alpha pride domain (pride in the self) bipolar patients scored 2.2 points less than the comparative group (all the above differences were statistically significant with a $\mathrm{p}<0.05$ ). For the Beta pride domain we did not find any difference in means.

In the case of the Sensitivity to Reward domain we did not either find any difference in means among the groups.

When correlating the Sensitivity to Reward with the remaining domains of the TOSCA we found the following statistically significant correlations. Sensitivity to Reward correlated 0.694 with alpha pride in Bipolar patients, -0.532 with guilt in schizophrenics, and in the comparative group correlated 0.267 with externalization of blame, 0.330 with Alpha pride (pride in self) and 0.211 with Beta pride (pride in behaviour).

\section{Discussion}

\section{The positive relation between shame and Sensitivity to Punish- ment}

Among the questionnaires used to measure shame and relate variables are "Cheek's Shyness Scale" ", the "Liebowitz Social Anxiety Scale" etc. the "Disinhibition and Boredom Susceptibility Scale", and the "Retrospective Self-Report of Behavioral Inhibition" (RSRI) and by Tangney's et al. "Self-Conscious Affect and Attribution Inventory (SCAAI)" and the "Test of Self-Conscious Affect"16-20. We decided to use the TOSCA, developed by Tangney before the instruments just mentioned because it integrates different theoretical visions and allows for a comprehensive measurements of various related states and traits ${ }^{17}$.
In relation to reward and punishment some instruments measure neighbour concepts such as the "Cloninger Harm Avoidance scale" 21 or the items in the "Sensation-Seeking Scale" related to disinhibition. We chose the Torrubia et al.'s SPS because we considered it a valid and simple instrument to be used with normal subjects and (what is more difficult to achieve) with psychiatric patients.

We have found, as expected, a statistically significant correlation between Sensitivity to Punishment, and Shame proneness both in normal subjects as in psychiatric patients.

There are many works that study behavioral inhibition, shyness, social anxiety and passive isolation in normal subjects, but few in patients. Behavioral inhibition faced with the unknown refers to the inhibition in social and non social situations while shyness is only present in social relations and not in those that are non social. Both are associated with anxiety in children and in adults. This findings have not been replicated in relation to shame in our research. However, there was a non significant negative relation relationship between age and shame.

As for borderline and personality disorders there was a lower shame score although no reaching a statistically significant level.

The relation between depression and shame proneness was statistically significant, as has been evidenced in past studies ${ }^{17}$. There was a significant difference higher Sensitivity to Punishment in patients with Major Depression than in control subjects. This could be explained in line with Gray's theory of the existence of specific neurophysiologic system influencing sensitivity to inhibiting events and the findings relating sensitivity to punishment ${ }^{22}$ to neuroticism.

Shame and Guilt correlated in the TOSCA and the Major Depressive patients scores 
higher on both domains. One should distinguish between guilt and feeling guilty, given that a guilty person may not experience such a feeling whilst an innocent person may be overwhelmed with feelings of unjustified guilt. "The feeling of guilt is a deeply individualist emotion, a matter of self scrutiny and self condemnation (...) is the state attributed to a person that has acted moral or legally wrong ${ }^{23}$.

Bipolar and schizophrenics patients showed lower scores in Shame than depressives (means $40.53 \pm 9.72$ vs. $43.44 \pm 8.75$ ) and controls. The contrary states, Disinhibition and Shamelesness have been repeatedly described $^{24,25}$ in schizophrenic disorder and in the manic stages of Bipolar Disorder, especially during the excitomotor crisis, in the context of other unconnected behaviour (gluttony, exhibition, turbulence, violence). Some Bipolar II Disorders have been tentatively grouped with Schizophrenic Disorders in the context of the so called Schizoid spectrum. Our findings should be replicated and studied on the light of other parameters, among them biological correlations as we comment later.

\section{Limitations}

Our results might have been affected by the difference in age between the psychiatric sample and the comparative group. Partial correlations between shame and sensibility to punishment controlling for age showed that aged did not play a statistically significant role in the relation of these two domains in any of the five diagnostic groups, neither did in the comparative group. Only anxious patients showed a negative correlation $(r=$ $0.59, \mathrm{p}=0.02$ ) between Sensitivity to Punishment and age. In the case of controls, guilt proneness showed a small positive correlation with age $(r=0.22, \mathrm{p}<0.05)$, and for the schizophrenics age was also related with guilt proneness $(r=0.55, \mathrm{p}=0.035)$. Since our main aim of the study was to evaluate the relation of the proneness to shame with the Sensibility to Punishment, we consider that the lack of influence of age evidenced by the partial correlations, give support to our conclusions. Nevertheless it is generally favorable to have a comparative sample that differs the least in sociodemographic characteristics from the group of study.

\section{Future research}

A number of recent studies confirm suspicions of a hereditary tendency in shyness, shame and inhibition.

Low levels of serotonin are related to submissive behaviour. Dopamine hyperactivity has been associated with social phobia and with deficiencies in the prize and incentive functions ${ }^{26}$.

On the contrary ${ }^{26}$ a group of males with a high score in a factor made up of 'search for experiences', disinhibition and tendency to boredom showed significantly higher levels of testosterone and free androgens.

We are at present studying the relation of shame with the turnover of dopamine specifically through the metabolism of homovalinic acid.

On the extreme pole, in recent works ${ }^{27-33}$ some of us have outlined that shameless attitudes can appear in the course of neuropsychiatric illnesses and specific perversions, under the form of disinhibition and exhibitionism. In other cases, shamelessness is a stance with creative connotations, or, alternatively, alienating, taking the form of obscenity and pornography, which we also recently dealt with ${ }^{34}$. Disinhibition is a particular feature of organic brain disorders, occasionally producing the reappearance of undesirable behaviors that were previously inhibited during socialization. Disnihibition is a visible 
and relatively simple sign that can be reliably measured thru different instruments such as the Disinhibition and Boredom Susceptibility Scales, some items of the Sensation-Seeking Scale, the Retrospective Self-Report of Behavioral Inhibition (RSRI), etc.

For an easier understanding of the above behaviour patterns with psychiatric disorders, instead of shorter categorial diagnoses, such as those used in present classifications, there is a tendency to propose dimensional diagnoses in a continuum. This alternative gives us a better understanding of the heterogeneous nature of the symptoms, the lack of clear borders between diagnoses, better detection of symptoms and sub-threshold traits, and quantification of the symptoms. Factorial analysis then finds the main dimensions underlying the variables, and identifies the personality traits involved.

Future studies in the field should use dimensional diagnoses besides the categorial ones.

\section{References}

1. Honderich T, editor. Enciclopedia Oxford de Filosofía. Madrid: Tecnos; 2001.

2. Heiser N, Turner S, Beidel D. Shyness: relationship to social phobia and other psychiatric disorders. Behav Res Ther 2003; 41(2): 209-221.

3. Coplan R, Prakash K, O'Neil K, Armer M. Do you "want" to play? Distinguishing between conflicted shyness and social disinterest in early childhood. Dev Psychol 2004; 40(2): 244-258.

4. Chavira D, Stein M, Malcarne V. Scrutinizing the relationship between shyness and social phobia. J Anxiety Disord 2002; 16(6): 585-98.

5. Porot A. Manuel Alphabétique de Psychiatrie. Paris: PUF; 1969.

6. Torrubia R, Tobena A. A Scale for the Assessment of Susceptibility to Punishment as a Measure of Anxiety Preliminary-Results. Pers Indiv Differ 1984; 5(3): 371-5.
7. Angermeyer MC, Classen D, Majcher-Angermeyer A, Hofmann J. Stigmatisierung psychisch Kranker : Stadt versus Land. Psychother med Psychol 1985; 35: 99-103.

8. Ferguson T, Crowley SL. Measure for measure: Guilt is not a unitary construct. Journal of Personality Assessment 1997; 69: 425-441.

9. Tangney J, Wagner P, Gramzow R. Proneness to shame, proneness to guilt, and psychopathology. J Abnorm Psychol 1992; 101(3): 469-478.

10. Torrubia R, Avila C, Molto J, Caseras X. The Sensitivity to Punishment and Sensitivity to Reward Questionnaire (SPSRQ) as a Measure of Gray's Anxiety and Impulsivity Dimensions. Pers Indiv Differ 2001; 31(6): 837-62.

11. Tangney J, Wagner P, Gramzow R. The test of SelfConscious Affect (TOSCA). George Mason University: Fairfax, VA. 1989.

12. Adams S, Pitre N. Who uses bibliotherapy and why? Can J Psychiatry 2000; 45(7): 645-9.

13. Las Hayas C, Guillén V, Gonzaléz-Pinto A, Zamega G, Guimón J. Preliminary validation in spanish of the Test of self-conscious affect (TOSCA). Avances en Salud Mental Relacional/ Advances in relational mental health. Avalaible in: http// www.bibliopsiquis.com/asmr/0403/index.htm.

14. Althaus D, Hegerl U. Evaluation of suicide prevention measures. Current state of research and resulting implications (in German). Nervenarzt 2001; 72(9): 677-84.

15. Caseras X, Avila C, Torrubia R. The Measurement of Individual Differences in Behavioural Inhibition and Behavioural Activation Systems: a Comparison of Personality Scales. Pers Indiv Differ 2003; 34(6): 999-1013.

16. Sakuragi T. Association of culture with shyness among Japanese and American university students. Percept Mot Skills 2004; 98(3 Pt 1): 803-13.

17. Tangney J. Conceptual and methodological issues in the assessment of shame and guilt. Behav Res Ther 1996; 34(9): 741-54

18. Tangney J, Miller R, Flicker L, Barlow D. Are shame, guilt, and embarrassment distinct emotions? J Pers Soc Psychol 1996; 70(6): 1256-69.

19. Tangney J, Niedenthal P, Covert M, DH. B. Are shame and guilt related to distinct self-discrepancies? A test of Higgins's (1987) hypotheses. J Pers Soc Psychol 1998; 75(1): 256-68.

20. Tangney J, Wagner P, Gramzow R. Proneness to shame, proneness to guilt, and psychopathology. J Abnorm Psychol 1992; 101(3): 469-78.

21. Battaglia M, Ogliari A, Zanoni A, Villa F, Citterio A, Binaghi F, et al. Children's discrimination of expressions of 
emotions: relationship with indices of social anxiety and shyness. J Am Acad Child Adolesc Psychiatry 2004; 43(3): 358-65.

22. Abrams K, Yune S, Kim S, Jeon H, Han S, Hwang J, et al. Trait and state aspects of harm avoidance and its implication for treatment in major depressive disorder, dysthymic disorder, and depressive personality disorder. Psychiatry Clin Neurosci 2004; 58(3): 240-248.

23. Spaemann R. Basic moral concepts. London; 1989.

24. Guimón J. Psicopatología de la desvergüenza. Psiquis 2004; 25(1): 33-41.

25. Guimón J. Exhibicionismo. Actitud y Perversión. Revista de terapia sexual y de la pareja 2004(19): 70-82.

26. Schneier F, Blanco, C., et al. The social anxiety spectrum. Psychiatr Clin North Am 2002; 25(4): 757-74.

27. Guimón J. La desvergüenza. El Correo 200413 de marzo; Sect. 19.

28. Guimón J. Psicopatología de la desvergüenza. Psiquis 2004; 25(1): 29-36.

29. Guimón J. Pornografía y Salud Mental. Jano Humanidades Médicas 2004; 67(In press).
30. Guimón J. Aspectos psicopatológicos de la desinhibición. Revista de la Asociación Española de Neuropsiquiatría 2004.

31. Guimón J. Art et Psychiatrie. Genève: Goerg; 2004.

32. Guimón J. Exhibicionismo:actitud y perversion. Revista de terapia sexual y de pareja 2004(19): 70.

33. Guimón J. Dalí:¿Locura o desfachatez? Jano 2005 11-17 febrero: 378-380.

34. Guimón J. La desvergüenza: Entre el pudor y la obsecenidad. Madrid: Espasa Hoy; 2005.

Address for correspondence:

José Guimón, M.D.

Catedrático de Psiquiatría.

Departamento de Neurociencias. Psiquiatría.

Facultad de Medicina y Odontología

Universidad del País Vasco.

C/ Barrio de Sarriena, s/n.

E-48940 Lejona (Vizcaya)

Mail: onpguugj@lg.ehu.es 